\title{
MR
}

\section{Genetic differentiation of Octopus minor (Mollusca, Cephalopoda) off the northern coast of China as revealed by amplified fragment length polymorphisms}

\author{
J.M. Yang ${ }^{1}$, G.H. Sun ${ }^{1}$, X.D. Zheng' ${ }^{2,3}$, L.H. Ren ${ }^{1}$, W.J. Wang', G.R. Li ${ }^{1,4}$ \\ and B.C. Sun ${ }^{5}$
}

${ }^{1}$ Shandong Marine Resource and Environment Research Institute, Yantai, China ${ }^{2}$ Fisheries College, Ocean University of China, Qingdao, China

${ }^{3}$ Institute of Evolution and Marine Biodiversity, Ocean University of China, Qingdao, China

${ }^{4}$ Fisheries and Life Science College, Shanghai Ocean University, Shanghai, China

${ }^{5}$ Freshwater Fisheries Research Institute of Linyi, Linyi, China

Corresponding author: X.D. Zheng

E-mail: xdzheng@ouc.edu.cn

Genet. Mol. Res. 14 (4): 15616-15623 (2015)

Received January 9, 2015

Accepted May 18, 2015

Published December 1, 2015

DOI http://dx.doi.org/10.4238/2015.December.1.13

\begin{abstract}
Octopus minor (Sasaki, 1920) is an economically important cephalopod that is found in the northern coastal waters of China. In this study, we investigated genetic differentiation in fishery populations using amplified fragment length polymorphisms (AFLPs). A total of 150 individuals were collected from five locations: Dalian (DL), Yantai (YT), Qingdao (QD), Lianyungang (LY), and Zhoushan (ZS), and 243 reproducible bands were amplified using five AFLP primer combinations. The percentage of polymorphic bands ranged from 53.33 to $76.08 \%$. Nei's genetic identity ranged from 0.9139 to 0.9713 , and the genetic distance ranged from 0.0291 to 0.0900 . A phylogenetic tree was
\end{abstract}


constructed using the unweighted pair group method with arithmetic mean, based on the genetic distance. The DL and YT populations originated from one clade, while the QD, LY, and ZS populations originated from another. The results indicate that the $O$. minor stock consisted of two genetic populations with an overall significantly analogous $F_{\mathrm{ST}}$ value $(0.1088, \mathrm{P}<0.05)$. Most of the variance was within populations. These findings will be important for more sustainable octopus fisheries, so that this marine resource can be conserved for its long-term utilization.

Key words: Octopus minor; Population structure; North China coast; AFLP

\section{INTRODUCTION}

Cephalopods, commonly known as the octopuses, squids, and cuttlefishes, together with the vampire squid and Nautilus, are a well-defined class of Mollusca (Boyle and Rodhouse, 2005). There are about 700 described species of living cephalopods and around 17,000 fossil species (Brusca and Brusca, 1990). Octopuses are widespread in the world's oceans, from the poles to the tropics, and the genus Octopus accounts for one-third of the total number of cephalopod species (Huffard, 2007).

Octopus minor (Sasaki, 1920) is a benthic, littoral species that lives in the subtidal zone down to a depth of $150 \mathrm{~m}$, and is widely distributed in the coastal waters of China, the Korean Peninsula, as well as the Western Pacific waters of the Japanese archipelago (Okutani et al., 1987; Lu et al., 2012). Octopus variabilis has been used as a synonym for the species by some researchers (e.g., Yamamoto, 1942; Dong, 1988; Lu et al., 2012). It is an economically important cephalopod in northern China, because not only does it have a high protein content but also considerable medicinal value (Qian et al., 2010).

With exports to Korea and Japan, the fishing pressure on this species is increasing. To conserve it, it is imperative to understand its population structure and identify fishing limits, based on genetic data (Thorpe et al., 2000; Kang et al., 2012). Recently, the increased use of molecular markers, such as amplified fragment length polymorphisms (AFLPs), has revealed the genetic structures of marine populations (Luo et al., 2010). The importance of the genetic characterization of populations has led to the development of the "genetic stock concept" (Carvalho and Hauser, 1994).

An effective management program for the sustainable use and conservation of $O$. minor is necessary. Such a program requires knowledge of the present genetic status of the species, and the ability to monitor genetic changes caused by overharvesting. Its population biology is poorly documented (Gao et al., 2009); therefore, the objective of the present study was to use highly variable AFLP markers to evaluate the level of genetic variability and genetic structuring of $O$. minor off the northern coast of China.

\section{MATERIAL AND METHODS}

\section{Sample collection}

Samples were collected from five localities in the coastal waters of China: Dalian (DL, 
$\left.38.93^{\circ} \mathrm{N}, 122.02^{\circ} \mathrm{E}\right)$, Yantai $\left(\mathrm{YT}, 37.67^{\circ} \mathrm{N}, 121.17^{\circ} \mathrm{E}\right)$, Qingdao (QD, $\left.35.82^{\circ} \mathrm{N}, 120.37^{\circ} \mathrm{E}\right)$, Lianyungang $\left(\mathrm{LY}, 34.75^{\circ} \mathrm{N}, 119.83^{\circ} \mathrm{E}\right)$, and Zhoushan $\left(\mathrm{ZS}, 30.25^{\circ} \mathrm{N}, 122.64^{\circ} \mathrm{E}\right)$ from December 2007 to March 2008 (Table 1 and Figure 1). Thirty individuals were randomly selected from each population, and muscle tissue was cut from the mantle of each individual and stored in $1.5-\mathrm{mL}$ centrifuge tubes at $-80^{\circ} \mathrm{C}$.

Table 1. Number of samples, date, and average body weight $(\mathrm{g})$ of five geographic populations O.minor in the coastal waters of China.

\begin{tabular}{lcccc}
\hline Populations & Abbreviation & Number & Date & Average body weight $( \pm$ SD) \\
\hline Dalian & DL & 30 & 2008.01 .22 & $254.65 \pm 48.83$ \\
Yantai & YT & 30 & 2008.01 .23 & $263.11 \pm 36.41$ \\
Qingdao & QD & 30 & 2008.03 .26 & $257.42 \pm 58.74$ \\
Lianyungang & LY & 30 & 2007.12 .23 & $195.76 \pm 65.43$ \\
Zhoushan & ZS & 30 & 2008.01 .06 & $136.24 \pm 38.07$ \\
\hline
\end{tabular}

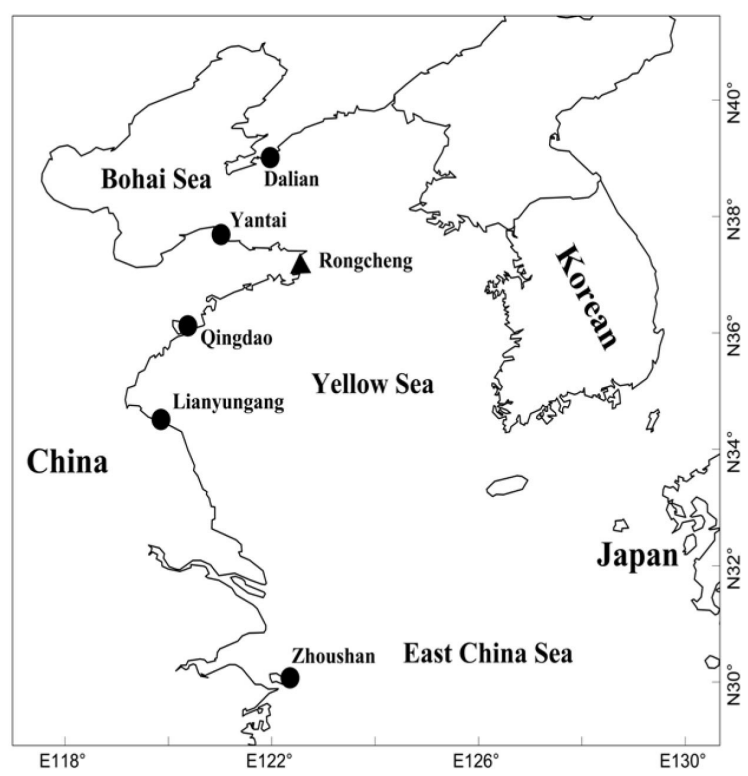

Figure 1. Sampling locations of Octopus minor along the coastal waters of China.

\section{DNA extraction and AFLP analysis}

Genomic DNA was extracted from 150 individuals from the five populations according to Sambrook et al. (1989) method. The extracted DNA was quantified by fluorimetry, and was then diluted to $25 \mathrm{ng} / \mu \mathrm{L}$. The AFLP analysis followed the modified protocol as described by Vos et al. (1995). The adapter and primer sequences are presented in Table 2. To check the reproducibility of the results and ensure the comparison of similar bands on the two gels required for the analysis of each primer combination, a sample of control DNA was included on the gels. In addition, several randomly selected accessions were reprocessed and run on separate gels. 
Table 2. Adapter and primer sequences used in AFLP analysis (Vos et al., 1995).

\begin{tabular}{ll}
\hline Primer/Adapter & Sequence (5'-3') \\
\hline EcoRI-adapter & 5'-CTCGTAGACTGCGTACC-3' \\
MseI-adapter & 3'-CTGACGCATGGTTAA-5' \\
& 5'-GACGATGAGTCCTGAG-3' \\
EcoRI-adapter & 3'-ACTCAGGACTCAT-5' \\
MseI-adapter & GACTGCGTACCAATTC- \\
\hline
\end{tabular}

\section{Data analysis}

For each gel generated from each primer pair, the numbers of observable and monomorphic AFLP bands were counted. Clear polymorphic AFLP bands were scored as 1 (present) or 0 (absent). The bands were first analyzed for AFLPs by counting the number of polymorphic bands and calculating their frequencies with respect to the primer pairs, samples, and populations. To compare AFLPs between the populations, the numbers of polymorphic bands were plotted against their frequencies of occurrence in each population.

Calculations of heterogeneity or total genetic diversity were conducted according to Nei and Li (1979). For this estimation, each band was considered as a biallelic locus, so that if a band was present it was one allele, and if it was absent it was the alternative allele. The parameters $P$ (percentage of polymorphic bands), $H$ (Nei's gene diversity), and $I$ (Shannon's Information index) were separately analyzed using POPGENE 1.31 (Yeh et al., 1999). The five geographical populations were clustered using the unweighted pair group method with arithmetic mean (UPGMA) in MEGA 4.1 (Tamura et al., 2007).

Analysis of molecular variance (AMOVA; Excoffier et al., 1992) of AFLP variation between populations was performed using Arlequin 3.0 (Excoffier et al., 2005). The value of $F_{\text {ST }}$ was also ascertained.

\section{RESULTS}

\section{AFLP variation}

A total of 243 AFLP bands were amplified from the five AFLP primer pairs (Table 3 ). The number of observable bands per primer pair ranged from 42 to 60 , with an average of 48.6. $P$ ranged from 53.33 to $76.08 \%$. No AFLP band was found to be specific to only one population, and the number of polymorphic bands differed between primer pairs. The number of AFLP bands obtained from the primer pair E-ATG/M-CCT was the highest, and the bands from the primer pair E-ACA+M-CAT had the highest $P(76.08 \%)$. There were 155 polymorphic bands among the 243 AFLP bands, and $P$ was $63.79 \%$.

\section{AFLP diversity between populations}

A comparison of AFLP band genetic diversity in the five populations was performed (Table 4). The QD population had the highest $H$ value $(H=0.3075)$, and the YT population has the lowest $(H=0.2374)$. $I$ values exhibited the same pattern $(\mathrm{QD}, I=0.4552$; YT, $I=0.3528)$. The results demonstrate that all of the populations had a high genetic diversity, but the QD 
population was more diverse than the others.

Table 3. Number of bands generated by primer combinations.

\begin{tabular}{lccc}
\hline Primer pair & No. of AFLP bands & No. of polymorphic bands & Percentage of polymorphic bands \\
\hline E-AAC/M-CTT & 42 & 28 & 66.67 \\
E-ACA/M-CAT & 46 & 35 & 76.08 \\
E-ATG/M-CCT & 60 & 32 & 53.33 \\
E-ATG/M-CTG & 42 & 26 & 61.90 \\
E-ACT/M-CAC & 53 & 34 & 64.15 \\
Total & 243 & 155 & 63.79 \\
Average & 48.6 & 31 & \\
\hline
\end{tabular}

Table 4. Genetic diversity of five geographical populations of Octopus minor.

\begin{tabular}{lccc}
\hline Population & Observed No. of alleles $\left(N_{\mathrm{A}}\right)$ & Nei's gene diversity $(H)$ & Shannon's Information index $(I)$ \\
\hline DL & 1.6451 & 0.2476 & 0.3671 \\
YT & 1.6203 & 0.2374 & 0.3528 \\
QD & 1.8057 & 0.3075 & 0.4552 \\
LY & 1.6667 & 0.2681 & 0.3926 \\
ZS & 1.6498 & 0.2417 & 0.3599 \\
\hline
\end{tabular}

Among the five geographically different populations, Nei's genetic identity (Table 5) ranged from 0.9139 to 0.9713 , and the genetic distance ranged from 0.0291 to 0.0900 . The genetic distance between QD and LY was the shortest (0.0291), and between DL and ZS was the longest (0.0900). The highest Nei's genetic identity was between QD and LY (0.9713), and the lowest was between DL and ZS (0.9139), indicating that differentiation between QD and LY was lower than that between the other populations.

Table 5. Nei's genetic identity (above diagonal) and genetic distance (below diagonal) of Octopus minor.

\begin{tabular}{lccccc}
\hline & DL & YT & QD & LY & ZS \\
\hline DL & - & 0.9463 & 0.9184 & 0.9234 & 0.9139 \\
YT & 0.0552 & - & 0.9256 & 0.9364 & 0.9299 \\
QD & 0.0852 & 0.0773 & 0.9262 \\
LY & 0.0797 & 0.0657 & 0.0291 & 0.9713 & 0.9617 \\
ZS & 0.0900 & 0.0727 & 0.0767 & 0.0391 & - \\
\hline
\end{tabular}

Based on the $F_{\mathrm{ST}}$ estimation from the AMOVA (Table 6), 10.88\% of the variation was between populations and $89.12 \%$ was within populations. Therefore, the diversity between populations was much lower than within populations.

Based on the AFLP data, an UPGMA tree was constructed based on the five populations (Figure 2). The five populations could be classified into two clades: the DL and YT populations may have originated from one clade, while the QD, LY, and ZS populations originated from another. 
Table 6. Analysis of molecular variance (AMOVA) among 5 populations of Octopus minor.

\begin{tabular}{lrccc}
\hline Source of variation & d.f. & Sum of squares & Variance components & Percentage of variance \\
\hline Among populations & 4 & 494.067 & $3.15749^{\mathrm{Va}}$ & 10.88 \\
Within populations & 145 & 4174.833 & $28.79195^{\mathrm{Vb}}$ & 89.12 \\
Total variation & 149 & 4668.900 & 31.94944 & \\
\hline
\end{tabular}

$F_{\text {ST }}=0.1088(\mathrm{P}<0.05)$.

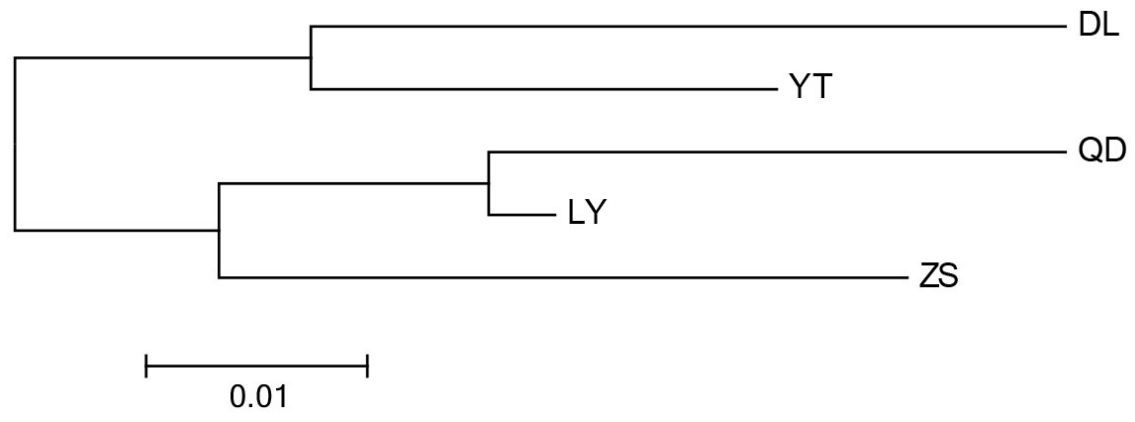

Figure 2. UPGMA tree of the five geographic populations in Octopus minor.

\section{DISCUSSION}

\section{Genetic diversity of $O$. minor}

To our knowledge, this is the first study that has attempted to assess the genetic diversity and population structure of $O$. minor using AFLP markers. Five highly polymorphic and reproducible primer pairs were selected. The overall percentage of polymorphic loci in the five populations was $63.79 \%$, which is much higher than the data obtained for allozyme loci (20-30\%) (Gao et al., 2009) and mitochondrial cytochrome $c$ oxidase subunit I sequences (Sun et al., 2010), but is similar to that found for Octopus ocellatus (62.03 to 67.93\%) that was analyzed by six AFLP primer combinations (Zhang et al., 2009). This result demonstrates that AFLP obtained more information than the other two methods of genetic diversity analysis.

\section{Intraspecific population differentiation and limited gene flow of $O$. minor}

In the present study, the genetic distance between the five geographical groups ranged from 0.0291 to 0.0900 , which is greater than the data obtained from COI sequences $(0.0029$ 0.0077) (Sun et al., 2010). However, the topologies of the neighbor-joining and UPGMA phylogenetic trees that were based on the COI sequences were similar to the tree constructed by AFLP, and both approaches indicated that the five populations were clustered into two major clades. The DL and YT populations may have originated from one clade, while the QD, LY, and ZS populations originated from another. Chang et al. (2010) analyzed seven geographical populations of this species based on COI sequences, and placed DL, YT, QD, LY, and ZS into the same group.

On the basis of the results of the present study, $O$. minor stock should be regarded as two different genetic populations $\left(F_{\mathrm{ST}}=0.1088\right)$. The reasons for this may be related to the 
ecological environment, geographical conditions, or $O$. minor breeding behavior. Shandong Peninsula may be a natural barrier to gene exchange. In addition, bottom-dwelling in shallow coastal waters and troglodytism could also result in the limited migration of $O$. minor. Therefore, gene flow is difficult between individuals in the Yellow Sea and the Bohai Sea (Palumbi, 2003). From a management perspective, these genetically isolated populations should be treated as separate management units. Stock enhancement to ameliorate the effects of overexploitation of natural $O$. minor populations should be conducted using local populations as founders.

Zuo et al. (2011) used 12 microsatellite DNA markers to estimate the $O$. minor population at Rongcheng $\left(37.16^{\circ} \mathrm{N}, 122.41^{\circ} \mathrm{E}\right)$ (Figure 1), which is located between YT and QD. Further studies will provide more information about the two genetic populations (Gao, 2014).

\section{ACKNOWLEDGMENTS}

We thank G.S. Qi of the Ocean University of China and Z.B. Huang of Xiamen University for assistance with sample collection and data analysis. We also thank K.M. Warnke (Freie Universität Berlin, Germany) and H. Chuan-Wen (Chung-Hsing University) for valuable comments. Research supported by grants from the National Natural Science Foundation of China (\#31172058), the Yantai Science and Technology Development Program (\#2011068), the Agricultural Breeding Project of Shandong Province (\#2014-2017), and the National Marine Public Welfare Research Project (\#201305043).

\section{REFERENCES}

Boyle PR and Rodhouse PG (2005). Cephalopods: ecology and fisheries. Blackwell Science, Oxford, 1-6.

Brusca RC and Brusca GJ (1990). Invertebrates. Sinauer Associates Inc., Sunderland.

Carvalho GR and Hauser L (1994). Molecular genetics and the stock concept in fisheries. Rev. Fish. Biol. Fisher. 4: 326-350.

Chang KM, Li H, Lü ZM and Chi CF (2010). Genetic variation in different populations of Octopus variabilis in China coastal waters based on the COI gene analysis. Oceanol. Limnol. Sin. 41: 307-314.

Dong ZZ (1988). Fauna Sinica, Phylum Mollusca, Class Cephalopoda. Science Press, Beijing, 181-182.

Excoffier L, Smouse PE and Quattro JM (1992). Analysis of molecular variance inferred from metric distances among DNA haplotypes: application to human mitochondrial DNA restriction data. Genetics 131: 479-491.

Excoffier L, Laval G and Schneider S (2005). Arlequin (version 3.0): an integrated software package for population genetics data analysis. Evol. Bioinform. Online 1: 47-50.

Gao XL (2014). Studies on population genetics of Octopus minor located in the waters of China. Master's thesis, Ocean University of China.

Gao Q, Zheng XD, Kong LF, Wang ZP, et al. (2009). Biochemical genetic analysis of wild populations of Octopus variabilis. J. Ocean. Univ. Chin. 39: 1193-1197.

Huffard CL (2007). Four new species of shallow water pygmy octopus (Mollusca: Cephalopoda) from the Kingdom of Tonga. Molluscan Res. 27: 147-170.

Kang JH, Kim YK, Park JY, An CM, et al. (2012). Development of microsatellite markers to genetically differentiate populations of Octopus minor from Korea and China. Mol. Biol. Rep. 39: 8277- 8286.

Lu CC, Zheng XD and Lin XZ (2012). Diversity of Cephalopoda from the waters of the Chinese mainland and Taiwan. In: Proceedings of the 1st Mainland and Taiwan symposium of marine biodiversity studies (Lin M and Wang CG, eds.). Ocean Press, Beijing, 76-87.

Luo X, Ke C, You W, Wang D, et al. (2010). AFLP analysis of populations of Haliotis discus hannai, Haliotis gigantea, and their hybrids. J. Shellfish Res. 29: 731-734.

Nei M and Li WH (1979). Mathematical model for studying genetic variation in terms of restriction endonucleases. Proc. Natl. Acad. Sci. U. S. A. 76: 5269-5273.

Okutani T, Tagawa M and Horikawa H (1987). Cephalopods from continental shelf and slope around Japan: the intensive research of unexploited fishery resources on continental slopes. Japan Fisheries Resource Conservation Society, Tokyo, 164-165. 
Palumbi SR (2003). Population genetics, demographic connectivity, and the design of marine reserves. Ecol. Appl. 13: 146-158.

Qian YS, Zheng XD, Wang P and Li Q (2010). Analysis and evaluation of nutritive composition of Octopus minor in Lake Swan. Mar. Sci. 34: 14-18.

Sambrook J, Fritsch EF and Maniatis T (1989). Molecular cloning: a laboratory manual (2nd eds.). Cold Spring Harbor Laboratory Press, Cold Spring Harbor.

Sun BC, Yang JM, Sun GH, Liu XQ, et al. (2010). Sequence and molecular phylogeny of mitochondrial COI gene fragment in five populations of Octopus variabilis in China. Oceanol. Limnol. Sin. 41: 259-265.

Tamura K, Dudley J, Nei M and Kumar S (2007). MEGA4: Molecular evolutionary genetics analysis (MEGA) software version 4.0. Mol. Biol. Evol. 24: 1596-1599.

Thorpe J, Solé-Cava AM and Watts PC (2000). Exploited marine invertebrates: genetics and fisheries. Hydrobiologia 420: 165-184.

Vos P, Hogers R, Blecker M, Reijans M, et al. (1995). AFLP: A new technique for DNA finger printing. Nucleic Acids Res. 23: 4407-4414.

Yamamoto T (1942). On the ecology of Octopus variabilis typicus (Sasaki), with special reference to its breading habits. (In Japanese with English abstract) Jap. J. Malacol. 12: 9-20.

Yeh JC, Yang R and Boyle T (1999). POPGENE version 1.31: Microsoft window-based freeware for population genetic analysis. University of Alberta, Edmonton.

Zhang LG, Yang JM, Liu XQ, Wang WJ, et al. (2009). The genetic diversity of Octopus ocellatus by AFLP markers. Oceanol. Limnol. Sin. 40: 803-807.

Zuo ZR, Zheng XD, Yuan Y and Li Q (2011). Development and characterization of 12 polymorphic microsatellite loci in Octopus minor (Sasaki, 1920). Conserv. Genet. Resour. 3: 489-491. 